\title{
A Social Theoretical Interpretation of Dai Zhen's Critique of Neo-Confucianism
}

\author{
Matthew M. Chew ${ }^{1}$ \\ ${ }^{1}$ Department of Sociology, Hong Kong Baptist University, Hong Kong, China \\ Correspondence: Matthew M. Chew, Department of Sociology, Hong Kong Baptist University, Kowloon Tong, \\ Kowloon, HKSAR, China. Tel: 852-3411-7132. E-mail: mmtchew@hkbu.edu.hk
}

Received: September 15, 2010 Accepted: February 3, 2012 Online Published: July 1, 2012

doi:10.5539/ach.v4n2p22

URL: http://dx.doi.org/ach.v4n2p22

\begin{abstract}
This study analyzes and evaluates the social thought of Dai Zhen. It interprets Dai's thought in terms of a critique of ideology that problematizes Song dynasty Neo-Confucian moral vocabulary. Dai thinks that social critique is the ultimate goal of scholarship and he was explicit about this belief. This study will show that he analyzes the negative social consequences of Song Neo-Confucian moral discourse in sociologically sophisticated ways, and that he has developed this understanding through a series of works that began with Yuanshan (The Origin of Goodness) and ended with Mengzi Ziyi Suzheng (Commentaries on the Meaning of Terms in Mencius). Contemporary social theorist and cultural critics should find Dai's work relevant because his deconstruction of the reified moral vocabulary of his times is postmodern in spirit and he elucidated how discourses can concretely impact on society.
\end{abstract}

Keywords: Dai Zhen, Neo-confucianism, social theory, Qing China

\section{Introduction}

Dai Zhen (1724-1777) has been a favorite topic of intellectual historical analysis in the early Twentieth Century and the last few decades (Li, 2005; Tiwald, 2008). His philosophical project, published mainly in Yuanshan (The Origin of Goodness) (thereafter represented by YS) and Mengzi Ziyi Suzheng (Commentaries on the Meaning of Terms in Mencius) (thereafter represented by SZ), has attracted many contested interpretations (Note 1). Scholars have approached Dai's thought from a broad range of perspectives including philology, ontology, ethics, social theory, human nature and psychology, culture, and epistemology. Among them, it is the perspective of social theory that is least well articulated. Part of the reason is that many Chinese scholars were previously pressured to interpret Dai's social thought in orthodox Marxist terms and international scholars tend to interpret it as crude utilitarianism (eg. Hu, 1986; Shao, 1985). More importantly, the majority of discussions of Dai's thought have been carried out exclusively on the basis of his contention with Neo-Confucian philosophy in the Song dynasty and interpretations of it, or Songxue (Song Learning).

However, as I will show in this study, Dai takes the social consequences of Song Neo-Confucian thoughts, rather than the contents of Song Neo-Confucian thoughts as such, to be the ultimate object of his critique. Hence exploring Dai's analysis of social problems resulted from Song Learning and his solutions to those problems are central to understanding of Dai's thought. This study will adopt this seldom explored perspective and interpret Dai's two theoretical treatises as a social theoretical critique of the ideological consequences of Song Neo-Confucian moral vocabulary.

\section{Characterizing Dai Zhen's Social Thought: An Ideological Critique of Song Neo-Confucianism}

Although the social relevance of Dai's thought has been recognized by numerous interpreters including Chinese Marxist ones, they have earned him not much more than the title of a 'materialist' philosopher and the reputation of being 'progressive.' Such interpretations are not invalid, but Dai can be appreciated more fully if scholars examine how exactly he directed and developed his social critique. I treat Dai's discussion of Song Neo-Confucianism as a critique of the undesirable social consequences which follows from the invention and subsequent cultural pervasiveness of a set of Song Neo-Confucian moral concepts (Note 2). In contemporary terminology, we may see such a project as deconstruction or a social theoretical critique of ideology. The concept 'critique of ideology' particular is useful for highlighting: i) how Dai understands the close relationship between 
society and thought, and ii) how that understanding motivated the development of his positions and arguments on social thought through time. Before illustrating these two aspects of Dai's thought, I will first define clearly what a 'critique of ideology' is.

This study borrows from the classical theory of ideology formulated by Karl Mannheim (Note 3). According to him, any cultural products can potentially function as ideology or contain ideology. Ideology can originate from a broad range of items, not only knowledge in the narrow sense but literature, thoughts, moral value, and other elements of 'superstructure.' Such a broad definition of ideology subsumes a range of different understandings of the generation and the mechanisms of ideology. At an extreme is the often criticized simplistic view: ideology as a piece of cultural artifact intentionally fabricated by an actor - who is often at the same time its benefactor for the sake of legitimating an otherwise illegitimate oppression on other action. Mannheim calls this understanding a 'partial' conception of ideology. Then there is the 'total' conception of ideology, referring to symbols produced by intellectuals that are utilized to legitimize the actions of certain actors, who may or may not be connected to the intellectuals who produce the ideology. In both these conceptions, the implication is that ideology reflects the material condition of society and that it is systematically sustained. But there is a significant difference between the first and second conceptions: the second does not at all suppose ideology is created in an intended and purposeful way by a dominant group for a particular purpose or for a particular occasion.

The third conception of ideology, the 'non-evaluative' one, also perceives ideology as legitimating devices for a dominant group's control over others. However, there is no determinate or law-like relationship between the producers and the benefactors of ideology, between social-economic circumstances and ideology, or between the original intentions of producers of ideology and the social consequences of those products. To understand such relationships for any particular ideology, one has to investigate the contents of that particular piece of ideology and the specific social circumstance in which the ideology pervades. The third conception of ideology is the most sophisticated and appropriate one for analyzing the cultural complexities of contemporary societies. I will show that Dai criticized the ideological mechanisms of Song Neo-Confucian moral vocabulary in a few different ways along these three understandings of ideology. I will first examine his earlier formulations in the YS, which are close to the 'partial' conception of ideology. More sophisticated formulations that resemble the second and third conceptions of ideology are reached in the SZ.

\section{Dai's Concern for the Negative Social Consequences of Song Neo-Confucian Moral Vocabulary}

The last six entries of Chapter 3 in YS deal explicitly with politics. These entries are markedly different from the other sections of the book, which mainly engage in philological discussion of philosophical vocabulary (Note 4). Entries 13 and 14 focus on the critique of the xiaoren (ie. inferior and evil people, the opposite of junzi (gentlemen). Among the deeds of the xiaoren, he emphasizes how their 'obsequiousness' and 'wickedness' can deceive the ruler and bring ruin to the people. However, such a critique seems slightly hackneyed and formalistic because Dai does not specify concretely how the xiaoren functions in socio-political ways. This may be the reason that relatively few have investigated into Dai's social thought and that those who did never make anything out of these two passages. But there are a few observations to be made here. Firstly, Dai demonstrates, though only vaguely, an emphasis of deception as a main cause to problems in governance. Secondly, if one takes into account Entry 12 in which Dai has explicitly denounced factionalism in the government, one may see that Dai was expressing dissatisfaction at his contemporary political arrangements through the dichotomy between the xiaoren and the gentlemen. Finally, in terms of the critique of ideology, Dai's adheres here to the 'partial' conception classified by Mannheim. He finds that the xiaoren is motivated to illegitimately grab political authority and xiaoren's efforts to mask that illegitimacy greatly help them to gain power.

If the social critique made in Entries 13 and 14 of YS seems a bit vague and irrelevant, the frequently cited passage in Entry 15 represent a more concrete formulation.

Those in position are usually indifferent to virtue and good at deception [...] a result is that the people also deceive and become unruly in return [...] [Social disorder] is not due to the people's nature, but the greed and cruelty [of those in high positions]. The origin of social disorder is seldom not derived from problems at the top. But then disorder often flows to the bottom and burden the masses below. [Song Neo-Confucians] does not understand this, so that they say "the deeds of the people are not virtuous." To blame the masses on this ground is a serious misunderstanding (Hu, 1986: 166).

When Dai refers to 'those in high positions,' he can be criticizing both the xiaoren and the monarch. He accuses those in position to be either guilty of being 'greedy' or 'cruel,' but he seems to be exculpating them from what the xiaoren is guilty of, namely, the premeditated intention to deceive. Dai suggests that si (selfishness) and bi (becloudedness) are the two major vices. "Those in position steal from the people" but they do not sense that they utilize the moral vocabulary of shan (virtue) inappropriately. Hence they truly "seriously misunderstand" 
and their problem is becloudedness. The xiaoren, in contrast, insidiously deceives and their problem is selfishness.

What is emphatic in this entry is Dai's demonstration of how the seemingly innocuous moral term, shan, can become a tool of self-assurance for those in political position. It is a device for displacing objection to the actual misdeeds done to the ruled. The positioning of this entry at the ending of the whole work is not accidental or insignificant. The philosophical engagement in Chapters 1 and 2 composes the theoretical basis of invalidating and undermining the conceptual integrity of the Song Neo-Confucian notion of shan. The bulk of Chapters 1 and 2 of YS is composed of a philosophical repudiation of the dichotomy between xingershang (the metaphysical) and xinge xia (the physical), the offering of alternative moral basis such as ziran (the natural) and bieran (the necessary), the intellectualization of ren (benevolence), li (ritual) and yi (righteousness), the argument that human desire as basically good, and the demonstration of desire's direct connection to nature, principle, and righteousness. These points are well explicated by contemporary philosophical exegesis of Dai's thought; I need not elaborate on them in this article.

All these threads of arguments would neatly weave together into his social critique when they are interpreted as the theoretical basis upon which he de-legitimizes the moral authority of the concept of shan. Against the conventional concept of shan, Dai proposes alternative basis of morality: desires which include "food, drink and sexual activities" and "the love of life and fear for death" (Hu, 1986: 164). His arguments against prioritizing the metaphysical over the physical, desires, and human nature do not only amount to a critique of the contents of Song Learning, but is also directed toward the destruction of moral and socio-political authority that the concept of shan offered to 'those in high positions.'

Dai's social critique of Song Neo-Confucian vocabulary as the main objective of his philosophical project may not have been lucidly and systematically enunciated in the YS, but it came to be explicitly expressed by the time he finished SZ in 1777. In the preface to SZ, Dai elaborates his purpose of engaging Song Neo-Confucianism through commenting on Mencius' self-justification of being contentious.

The reason [of Dai's being contentious] is that erroneous words do not just end with words. They change and influence the minds of people. A mind which is beclouded will do injury to the conducting of affairs and to government [...] Their [ie. the Song Neo-Confucians'] words have deeply influenced people's minds. Thus they are causing harm without the people ever being conscious of them (Hu, 1986: 164).

Dai concludes SZ with the same message. In the epilogue, he asks why he needs to attack the Song Neo-Confucians and he answers,

Alas! If the doctrines of these men did not do injury to practices and policies and result in great harm to the people, I would have honored them. Why do I dislike them? Because I worry about [their contamination of] people's minds (Hu, 1986: 238).

Dai repeatedly stated that his ultimate concern in attacking Song Neo-Confucianism is social critique. This is a point that contemporary interpreters have not taken sufficiently seriously. When we turn to Dai's last letters, one to an anonymous person and another to Duan Yucai, Dai showed a very similar attitude. He first admits that contentiousness is not a valuable thing because scholars "of his time should not do research for the mere purpose of developing alternative philosophies like the Song Neo-Confucians." But then he immediately quotes his favorite Mencius passage in full form in order to explain why he has to be contentious and to "develop an alternative philosophy' himself.

Mencius says, "What is generated in the mind can do injury to governance, what is carried out according to governance policies can hurt in practice." They [the Song Neo-Confucians] think that they have grasped the heavenly principles, but there are many people in the world who practically suffer from their mis-thinking (Hu, 1986: 256).

In one of the last pieces of Dai's written work, he recapitulated the orientation of his whole philological and philosophical project.

Song Neo-Confucians slighted evidential and philological scholarship, language, and words. [...] I have worked on these fields for more than 30 years, and clearly understand that the causes of order and disorder reside there [ie. words] (Hu, 1986: 257) (my italics).

It is remarkable that Dai did not revert to his often used framework of the relationship among the three elements of scholarship (philology, literature, and moral principles). He could have attributed the ultimate goal of scholarship to moral principles, but instead he specifically attributes it to social and political order in the previous citation (Note 5).

Dai's philological arguments in the SZ against the Song Neo-Confucian repertoire of moral vocabulary - most 
notably those made against li (principles), qi (the physical), yu (desires), xing (human nature), ren (benevolence), yi (righteousness), li (ritual), qing (emotions), and dao (the way) - form a theoretical basis that undermines of the moral persuasion of these concepts. These exercises are similar and parallel to Dai's intricate deconstruction of shan and other moral concepts in the YS. What Dai sought to achieve in his philological critique of Song Neo-Confucian vocabulary in SZ include: the reconciliation of li (principles) and qi (the physical), reconciliation between li (ritual) and yu (desires), the rescue of cai (utility), zhi (materiality), and xing (human nature) from being conceptualized as inherently evil, establishment of si (selfishness) and bi (decloudedness) as the major vices, opposition against the intellectualization of ancient Confucian terms such as qing (emotions), and the revival of classical Confucian concepts including chuan (weighing). On the philosophical and theoretical level of examination, there is a shift of critique from shan in YS to li (principles) in SZ. On the level of social critique, the most important shift from YS to SZ was that Dai supplied in SZ a detailed, concrete analysis of the intellectual production, social operation, and specific benefactors of Song Neo-Confucian moral concepts, which is what I will examine in the following section.

\section{Dai's Analysis of the Social Implications of Song Neo-Confucian Moral Vocabulary}

I will start with Dai's examination of the production of ideology. There are two accounts of the production of ideology in the YS. There is first the xiaoren who deceives those in ruling positions and who robs the people. In this case, ideology is simply the lies told by xiaoren for their own benefit. This is hence a 'partial' conception of ideology. Then there are 'those in high positions' who make insidious use of currently available, authoritative moral vocabulary such as shan. Dai did not discuss the exact origin of that vocabulary in YS, although it is presumably initiated by ancient Confucians. But in the SZ, Dai explicitly points his fingers at the Song Neo-Confucianists (especially $\mathrm{Zhu} \mathrm{Xi}$ ) accusing them as promoters of this ideology. Dai's shift from sympathizing with the Song Neo-Confucians in his early works towards vehement attacks of them in his later works has been well-documented. (Qian, 1980; Yu, 1977). It needs no elaboration. But it is important to notice that Dai changed his understanding of producers of ideology in this shift. His attack of Song Neo-Confucians was actually coordinated with an abandonment of his previous critique of the xiaoren and his 'partial' conception of ideology. Dai explains in SZ why he came to think that a critique focusing on the xiaoren is inadequate.

The harm which [...] xiaoren can do to future generations is quite obvious to everybody. The harm to future generations caused by those generally regarded as superior men of wisdom is not so obvious because people consider them correct and hasten to follow them. Their words deeply influence people's minds, thus causing seriously injury without anyone knowing it (Hu, 1986: 169-170).

Although Dai sees the Song Neo-Confucians as a culprit, he is not being sarcastic in reminding us that they are "gentlemanly philosophers." Dai claims that they have distorted classical Confucian concepts and produced ideology but does not impute to them the insidious power-hungry intentions of the xiaoren. Dai sees the producers of ideology as dissociated from the benefactors of it. Song Neo-Confucians did not illegitimately gain political power from the moral vocabulary they invented. Dai admits that the Song Neo-Confucians genuinely "carry out in their daily conduct what they profess" (Hu, 1986: 238).

Another observation of Dai's analysis of the production of ideology is that despite the seeming abruptness of his shift towards critiquing Song Neo-Confucians, there is logical continuity of it with earlier critiques in YS. The critique of moral vocabulary being used as the legitimating tool by dominant groups is already present in YS, as I have shown. Because Song Neo-Confucians produced the supportive moral vocabulary, they are inevitably responsible for the problems that the vocabulary causes. This logic alone may not be enough to prompt him to turn from an earlier reconciliatory stance regarding Han learning and Song learning to an all-out repudiation of Song learning, but it was a factor additional to intellectual pressures from Dai's fellow Han Learning scholars. The second part of Dai's ideological critique deals with how ideology operates. Dai provides a more sophisticated explanation of how ideology operates in SZ than in YS. Dai points out that Song Neo-Confucians' philosophical and philological reinterpretations of classical Confucianism have become the orthodoxy beginning from the Ming dynasty. This moral vocabulary pervaded even at the lowest strata of society.

Presently, even the stupidest of men - though boorish and crude - will often appeal to li (principles) whenever he makes a decision or starts a dispute with someone (Hu, 1986: 175).

Being widely available, Song Neo-Confucian moral vocabulary could be utilized by any socially dominant group and not just those in high office.

Thus those who rely on their imposing manners, who take advantage of their position of authority, and who are clever in speech are able to promote their [versions of] li (principles). Those who are weak, irresolute, and incapable of arguing convincingly are forced to yield to the other people's [versions of] li (Hu, 1986: 175). 
To illustrate the operation of Song Neo-Confucian ideology, Dai further draws attention to the ease with which Song Neo-Confucian moral concepts can be used for legitimation. Dai thinks that there is an inherent tendency of the Song concept of li to allow one to enforce one's personal, interested opinions as absolute and universal moral principles.

Since the Song, people learn [about Song Neo-Confucian moral vocabulary] from one other. It has become customary for people to think of li as if it were a thing acquired from heaven and endowed in one's heart-and mind. As a result, personal opinions are taken to be li ( $\mathrm{Hu}, 1986: 175)$.

The third part of Dai's critique of ideology investigates those who benefit from ideology. He does not think the Song Neo-Confucians were the major benefactors of Song Neo-Confucian moral vocabulary. The Xiaoren and the politically powerful (who included local social elites, members of the literati-officials class, and the imperial house) are benefactors but they are not the only ones. Dai emphasizes that in everyday practice, people from a wide range of social strata mobilize li to their advantage and/or to hurt others. Regardless of the absolute social positions of the agents involved, social interactions of many kinds are plagued by Song Neo-Confucian ideology.

The exalted reprove their inferior on the basis of li; elders reprove their juniors on the basis of li; the noble and rich also reprove ordinary folks on the basis of li ( $\mathrm{Hu}, 1986: 182)$.

Dai finds that in addition to the fully conscious benefactors and the semi-conscious one who purposefully utilized Song thought as ideology, there is also a morally different group of benefactors. This group genuinely intended to be moral and was otherwise upright, but they are misled by Song Neo-Confucian moral vocabulary to conduct and judge affairs in socially oppressive ways. This type of 'benefactors,' as Dai sees it, are actually as much a prey to ideology as those they unintentionally hurt.

Such a person may be honest and unselfish, but when it comes to making a decision or a judgment on another person, he relies on his own opinions and regards what he thinks is right to be right and what he thinks wrong to be wrong. Although he believes he is upright and serious and he treats evil as an enemy, he fails to realize that the circumstances of affairs are difficult to ascertain, and that it is easy to be partial and lose [an objective sense of] right and wrong. Consequently, others can frequently suffer injustice because of this person - without this person ever realizing his mistakes. Or perhaps after the [unjust] event he becomes awakened, but by then remorse would be of no help (Hu, 1986: 175; Chin and Freeman, 1990: 74).

He attaches great importance to this newly discovered group of unintended ideologues - it is illustrated in his prioritizing of the fight against bi (becloudedness) over that against si (selfishness). He claims that "in both ancient and contemporary times, there is no scarcity of stern and upright men who hold firmly to whatever everyone considers to be important and unimportant" (Hu, 1986: 231; Chin and Freeman, 1990: 166). He thinks that the specific problem with this group is not about corruption and selfishness, but the pursuit of virtue led astray by becloudedness. Hence he thinks dispelling becloudedness is practically and logically prior to countering selfishness.

The words of the sages have always encouraged men to search for what is the most correct, to see it and act upon it. In seeking for what is most correct, it is necessary first to know [what is most correct]. Any [teachings] that urge us to get rid of our selfishness instead of dispelling our becloudedness or that emphasize practice before knowledge is not the teaching of the sages (Hu, 1986: 235).

Dai's evolution from a critique of the xiaoren to that of morally upright actors misled by the Song Neo-Confucian moral concepts did not only intensify his denouncement of Song Learning's as heterodoxy. It represented a deepening of the understanding of how ideology affects society. In Chinese intellectual history, poignant appeals to root out certain thoughts by branding them as heterodox was common and claims that heterodox thoughts corrupt society and politics are also not rare. But to analyze the negative social mechanisms of heterodox thought is a step that many fervent defenders of Confucian orthodox have not taken.

After interpreting the contents of Dai's critique of ideology, it is time to evaluate whether the critique is tenable and justified. I have shown that Dai respects the personal moral uprightness of the Song Neo-Confucians. Whether he over-emphasizes the social consequences of Song Neo-Confucian moral vocabulary is an empirical historical question worth exploring. But if one grants that Dai's portrayal of Song Neo-Confucian moral concepts' problematic functioning in mid-Qing society is accurate, one can understand why he sees supplanting the moral vocabulary as a solution to social problems of his times. Solutions to these particular social problems required no military, political and economic battles, because no such actions can undermine Song Neo-Confucian moral vocabulary's pervasive influence. The confrontation is an intellectual one - that between the popular reputation of Song Learning and reaction of Han Learning scholars such as Dai Zhen. His sense of responsibility (or self-importance) can be glimpsed through his numerous exclamations when he refers to the 
social consequences of Song thought. He strived to undermine the formidable academic authority and the firmly established cultural popularity of Song Neo-Confucian moral vocabulary. And he saw it as the first step in moving Qing dynasty's social culture away from Song Neo-Confucianism and towards (a Han Learning reformulation of) classical Confucian moral discourse.

Dai's sense of urgency and his emphasis on social critique have caused him to abandon some of the proper procedures of philosophical argumentation. Most notably, he has been criticized for not fully engaging the fine points of Neo-Confucian thought, Buddhism, and Taoism. In this sense, Chan Wing-tsit's (1963) critique that Dai has misread the Neo-Confucians and Zhang Taiyan's (1978: 123) charge that Dai should have paid more serious attention to Legalism and Taoism are basically sound. Nevertheless, there are many instances of which an imperfect understanding of Song Neo-Confucianism is not fatal to Dai's social thought. For example, even if Dai was misled when he thought that "Song Neo-Confucians perceived principle as a reified thing" (Chan, 1963: 722), many of the arguments in Dai's social theoretical critique of Neo-Confucian ideology remain unaffected. For example, Dai's contention that the dichotomy of principle and desire created a powerful legitimating device for those in power to justify social injustice would still be intact.

\section{Conclusion}

The previous analyses have re-interpreted Dai Zhen's critique of Neo-Confucianism through the lens of social theory. I showed that Dai's thought can be understood as a critique of ideology that focuses on Song Neo-Confucian moral vocabulary. Evidences in Dai's texts have been presented to demonstrate that he was very concerned about social critique - more so than most of his interpreters have acknowledged. Dai has been primarily known as a philologist and only secondarily appraised as a social thinker by contemporary scholars. But I have shown that he regarded social critique as the ultimate goal of scholarship and he was explicit about this belief. It was uncommon for Late Imperial Chinese thinkers to dedicate so explicitly and deeply to social critique. This makes Dai one of the most intellectually distinctive and socially important thinkers in the Qing period, and this is recognized by his contemporaries and by current scholars.

The previous analysis also illustrated that Dai understanding of the negative social consequences of Song Neo-Confucian moral discourse is theoretically complex. He has developed these understanding through a series of works that began with YS and ended with SZ. Contemporary social and cultural critics should find Dai's work interesting and relevant. His deconstruction of the reified moral vocabulary of the time was quite postmodern in spirit and it elucidated how moral discourse subtly yet powerfully impact on society. Beyond this deconstructionist effort, however, Dai has also made serious efforts to reconstruct. In passages unexplored in this study, he attempted to build a socially desirable moral vocabulary based on his reinterpretations of classical Confucianism. He wished that these could substitute the Song Neo-Confucian vocabulary. How exactly Dai constructed this moral vocabulary and what its contents are will be meaningful topics for further research.

\section{References}

Chan, W. (1963). A Source Book in Chinese Philosophy. Princeton University Press.

Cheng, Z. (1969). Tai Chen's Inquiry into Goodness. Honolulu: East-West Center Press.

Ch'in, A., \& Mansfield, F. (1990). Tai Chen on Mencius. Yale University Press.

Li, F. (2005). Zhang, Liu, and Liang's comments and interpretations on Dai Zhen. Journal of Beijing Normal University (Social Science Edition), 2, 79-85.

Longhurst, B. (1989). Karl Mannheim and the Contemporary Sociology of Knowledge. Macmillan Press.

Mannheim, K. (1936). Ideology and Utopia: An Introduction to the Sociology of Knowledge. London: Routledge and Kegan Paul.

Hu, S. (1986). Dai Dongyuan De Zhexue. Taipei: Yuanliu.

Qian, M. (1980). Zhongguo Jin Sanbai Nian Xueshu Shi. Taipei: Commercial Press.

Tiwald, J. (2006). Acquiring 'Feelings that do not Err': Moral Deliberation and the Sympathetic Point of View in the Ethics of Dai Zhen. Dissertation. University of Chicago.

Yu, Y. (1977). Lun Dai Zhen Yu Zhang Xuecheng. Taipei: Huaxi chuban she.

Zhang, T. (1978). Zhang Taiyan zhuanji Ziliao (Vol. 4). Taipei: Tianyi chuban she.

Zhao, S. (1985). Dai Zhen zhexue zhongde bianzheng fa sixiang. Journal of Zhengzhou University, 2.

\section{Notes}

Note 1. Qian Mu thinks that Dai does not recognize the central meaning of classical Confucian thoughts. But Hu 
Shih thinks that Dai is too much constrained by the classical Confucianism. While many acknowledge Dai's anti-Song stance, Feng Youlan argues that Dai's thought resembled Wang Yangming's and Yu Yingshi shows that Dai was very much indebted to Zhu Xi. Although intellectual historians of Chinese political thought such as Hsiao Kung-ch'uen do not take Dai as a political thinker at all, China's Marxist interpreters of Dai, Hu Shi and Liang Qichao claim Dai had revolutionary social-political relevance. On the one hand, Zhang Taiyan deplores Dai's adherence to the Confucian tradition of neglecting Legalism. On the other, Fang Dongshu objects to Dai's deviation from the Confucianist emphasis on morality.

Note 2. The term 'Song Neo-Confucian thought' tends to conflate numerous Neo-Confucian thinkers together and as such it is not an accurate term for classifying philosophical thoughts. However, given that Dai Zhen often used the term 'Song Confucians' (songru) to collectively refer to Song dynasty Confucian scholars and scholarship. Dai takes the term to mean a range of Neo-Confucian moral vocabulary popularized in the Ming and mid-Qing periods. I do not adopt Dai's exact terminology in this paper. Instead I use the term 'Song Neo-Confucianists' to mean what Dai mean by songru.

Note 3. The fullest account of Mannheim's definition of different conceptions of culture is found is his (1936) Ideology and Utopia. Among his contemporary interpreters, the clearest and most systematic account is Brian Longhurst (1989).

Note 4. I base my translation of paragraphs of YS and SZ on Hu Shi (1986), Cheng Zhongying (1969), Ch'in Ann-ping and Mansfield Freeman (1990). Hence I provide citations of Dai's works in Hu Shi's version or the English versions.

Note 5. One could argue that when Dai talks about yili, he is implicitly referring to political and social arrangements in addition to moral ones, since personal and social ethics are not considered isolated from each other in Confucianism. But my point here is to highlight Dai's explicitness in attending to the social realm. 